\title{
Transphosphatidylation of sugar alcohols and its implications for the pathogenesis of diabetic complications
}

\author{
J. Nakamura ${ }^{1}$, S. A. Lattimer ${ }^{2}$, D. A. Greene ${ }^{1}$ \\ ${ }^{1}$ Department of Internal Medicine, University of Michigan, Ann Arbor, Michigan, USA \\ ${ }^{2}$ The Michigan Diabetes Research and Training Center, University of Michigan, Ann Arbor, Michigan, USA
}

Summary Glucose-induced sorbitol accumulation and attendant alterations in cellular myo-inositol and phosphoinositide metabolism have been invoked in the pathogenesis of diabetic complications; however, direct effects of sorbitol on membrane phospholipid composition or metabolism have never been evaluated. Phospholipase D catalyses the transphosphatidylation of ethanol into phosphatidylcholine to yield phosphatidylethanol, an "abnormal" phospholipid whose content in rat brain is increased by chronic ethanol ingestion. Analogous transphosphatidylation of sorbitol or other polyols whose concentration is elevated in diabetes was explored in vitro and in glucose-exposed cultured human retinal pigment epithelial cells. Phosphatidylcholine and varying concentrations of sorbitol, galactitol, mannitol and glucose were incubated with peanut phospholipase D in sodiun acetate buffer for varying time periods. Thin layer chromatography revealed new phospholipid bands whose hydrolysis by phospholipase D liberated a water-soluble compound that cochromatographed with sorbitol on gas-liquid chro- matography, and whose concentration increased in a time- and concentration-dependent fashion. Identical transphosphatidylation activity was demonstrated in a rat brain synaptosomal fraction. Phospholipase $\mathrm{D}$ hydrolysis of lipids from human retinal pigment epithelial cells constitutively overexpressing the aldose reductase gene yielded a sorbitol-like compound whose appearance was increased by glucose exposure and was decreased by an aldose reductase inhibitor. Thus, glucose-induced aldose reductase inhibitor sensitive sorbitol accumulation might induce the formation of "phosphatidylsorbitol" through a transphosphatidyl mechanism that may contribute to altered membrane phospholipid metabolism in diabetes. [Diabetologia (1994) 57: 11471153)

Key words Aldose reductase, aldose reductase inhibitor, diabetes mellitus, diabetes complications, phospholipase D, phospholipid metabolism, sorbitol, transphosphatidylation.
Increased metabolic flux through the polyol (sorbitol) pathway in diabetes is initiated by the concentration-dependent conversion of glucose to sorbitol by the high $\mathrm{K}_{\mathrm{m}}$, rate-limiting enzyme aldose reductase

Received: 22 November 1993

and in revised form: 4 July 1994

Corresponding author: Dr. D. Greene, 3920 Taubman Center, Box 0354, University of Michigan Medical Center, 1500 E. Medical Center Drive, Ann Arbor, MI, 48109-0354, USA

Abbreviations: PL-D, Phospholipase D; MEM, minimum essential medium; RPE, retinal pigment epithelial cells; CS, calf serum. [alditol: $\mathrm{NADP}^{+}$1-oxidoreductase (EC 1.1.1.21)], which is followed by the subsequent conversion of sorbitol to fructose by the low $\mathrm{K}_{\mathrm{m}}$ enzyme sorbitol dehydrogenase [L-iditol: $\mathrm{NAD}^{+}$5-oxidoreductase NADH oxo-reductase (EC 1.1.1.14)] [1]. In selected tissues in which glucose entry is not rate-limiting for its overall metabolism, polyol pathway activation by glucose is associated with depletion of myo-inositol from one or more of its intracellular metabolic pools, which may or may not be associated with a detectable decrease in overall cellular myo-inositol content [2-5]. Polyol pathway-induced myo-inositol depletion has been associated with alterations in phosphatidylinositol biosynthesis, phosphoinositide 
turnover, diacylglycerol content and phosphoinositide-mediated signal transduction $[2-4,6-8]$, but it is supposed that the effects of polyol pathway activation on membrane phospholipid metabolism may not all be attributable to depletion of intracellular myo-inositol [5, 9-11], suggesting that other metabolic linkages should be sought. Phospholipase D (PLD) activity can incorporate several hydrophilic aliphatic alcohols into their corresponding phosphodiglycerides by transphosphatidylation [12]. Phosphatidylethanol is an acidic phospholipid that accumulates in kidney, brain, and other organs of chronically ethanol-intoxicated rats $[13,14]$, and in a rat brain synaptosomal fraction incubated with ethanol [15]. The accumulation of phosphatidylethanol has been invoked as a possible mediator of adverse effects of ethanol ingestion including fetal alcohol syndrome [16]. The present study was undertaken to ascertain whether sorbitol undergoes similar transphosphatidylation by plant or mammalian PL-D, and whether phosphatidylsorbitol was detectable in human cells exhibiting brisk sorbitol accumulation and altered membrane function when exposed to an elevated concentration of glucose in vitro or in vivo $[4,8,17-20]$.

\section{Materials and methods}

In vitro incorporation of polyols into phospholipid. Peanut PL$\mathrm{D}(0.25 \mathrm{mg})$ was dissolved in $1 \mathrm{ml}$ of $0.1 \mathrm{~mol} / 1$ sodium acetate plus $0.1 \mathrm{~mol} / 1$ calcium chloride $(\mathrm{pH} 5.6)$, to which $2.5 \mathrm{mg}$ of egg phosphatidylcholine in $0.5 \mathrm{ml}$ of water-saturated diethylether was added. This mixture was incubated with $0-3.0 \mathrm{~mol} / \mathrm{l}$ sorbitol, $0.15 \mathrm{~mol} / 1$ galactitol, $0.5 \mathrm{~mol} / 1 \mathrm{mannitol}$, or $1.5 \mathrm{~mol} / \mathrm{l}$ glucose at room temperature for $0-4 \mathrm{~h}$ with vigorous mixing every $30 \mathrm{~min}$. At the end of the incubation, ether was removed by evaporation under a stream of nitrogen and the reaction terminated with the addition of $3.75 \mathrm{ml}$ of chloroformmethanol $(1: 2$, volume/volume). An additional $1.25 \mathrm{ml}$ of chloroform and $1.25 \mathrm{ml}$ of water were added and the phases allowed to separate. The chloroform phase was washed three times with $4.75 \mathrm{ml}$ of preequilibrated upper phase (upper phase of chloroform-methanol-water, 10:10:9), evaporated to dryness under a stream of nitrogen and reconstituted in $0.5 \mathrm{ml}$ of chloroform. In selected studies, $0.25 \mathrm{ml}$ out of $0.5 \mathrm{ml}$ of this crude unfractionated lipid extract ("-column") was directly subjected to thin layer chromatography as described below. The remaining extracts from ten incubations were pooled, evaporated to dryness under nitrogen and the residue was dissolved in $200 \mu \mathrm{l}$ of chloroform. The combined extract was applied to a $1.5 \mathrm{~g}$ sialic acid column equilibrated with chloroform and eluted with $10 \mathrm{ml}$ each of chloroform-methanol mixtures of $97: 3,47: 3,22: 3,4: 1$, and $2: 1$. Phospholipids containing polyols were present in the chloroform-methanol $4: 1$ and 2:1 eluates. These eluates werc pooled, cvaporated to dryness under nitrogen, and dissolved in chloroform. These column-purified samples ("+ column") and authentic standards of phosphatidic acid and phosphatidylcholine were applied to the origin of oxalated $20 \mathrm{~cm} \times 20 \mathrm{~cm}, 250-\mu \mathrm{m}$ thick, silica gel 60 plates, developed in a solvent system containing chloroform-methanol-acetic acid-water $(25: 15: 4: 2)$ and visualized by iodine vapor or heating with cupric acetate spray.
Identification of lipid-bound sorbitol. The chromatographed lipids were scraped, extracted three times with $2.0 \mathrm{ml}$ of chloroform-methanol $(2: 1)$, pooled, evaporated to dryness under nitrogen, reconstituted in $0.5 \mathrm{ml}$ of water-saturated diethylether, and hydrolysed by incubation with $0.25 \mathrm{mg}$ of peanut PL-D in $0.1 \mathrm{~mol} / \mathrm{l}$ sodium acetate plus $0.1 \mathrm{~mol} / \mathrm{l} \mathrm{calci-}$ um chloride $(\mathrm{pH} \mathrm{5.6)}$ at room temperature for $4 \mathrm{~h}$ with vigorous mixing every $30 \mathrm{~min}$. The liberated water-soluble compounds were converted to their trimethylsilyl ethers or aldonitrile acetate derivatives and analysed by megabore or capillary gas-liquid chromatography, as previously described $[17,21,22]$.

Production of lipid-bound sorbitol by rat brain synaptosomes. Rat brain synaptosomes were prepared by discontinuous density gradient centrifugation of rat forebrain homogenates according to the method of Cotman and Matthews [23]. 1-Palmitoyl-2- $\left[{ }^{14} \mathrm{C}\right]$ oleoyl-sn-glycero-3-phosphocholine $(2.5 \mathrm{mmol} / \mathrm{l}$, $1.67 \mathrm{Ci} / \mathrm{mol}$ ) dissolved in $0.5 \mathrm{ml}$ of water-saturated diethylether and $800 \mu \mathrm{g}$ of membrane protein were incubated with $1 \mathrm{ml}$ of $0.1 \mathrm{~mol} / \mathrm{l}$ sodium acetate, $0.1 \mathrm{~mol} / \mathrm{l}$ calcium chloride and $3.0 \mathrm{~mol} / \mathrm{l}$ sorbitol $(\mathrm{pH} 5.6)$ at room temperature for $90 \mathrm{~min}$. Lipids were extracted with chloroform-methanol, separated by thin layer chromatography as described above and located autoradiographically.

Detection of lipid-bound sorbitol in glucose-exposed human retinal pigment epithelial cells $(R P E)$. Primary lines of $\mathrm{RPE}$ cells were established and maintained by a modification of the method of Del Monte and Maumenee [24] as recently described in detail [17]. One cell line, RPE 91, was selected because of its enhanced metabolic sensitivity to glucose associated with its constitutive over-expression of the aldose reductase gene [25]. RPE 91 cells were replated at an initial density of $10,000 \mathrm{cells} / \mathrm{cm}^{2}$ in $10-\mathrm{cm}$ dishes in Minimum Essential Medium with $2.0 \mathrm{mmol} / \mathrm{l}$ L-glutamine (MEM) containing $20 \%$ calf serum (CS) and $5 \mathrm{mmol} / \mathrm{l}$ glucose for $24 \mathrm{~h}$ and equilibrated in MEM-5\% CS-5 mmol/1 glucose for $72 \mathrm{~h}$ before switching to experimental conditions consisting of MEM- $5 \%$ CS containing 5 or $20 \mathrm{mmol} / \mathrm{l}$ glucose with or without the aldose reductase inhibitor sorbinil $(10 \mu \mathrm{mol} / 1$ (Pfizer Central Research, Groton, Conn., USA), Medium was routinely changed every 2 days before and during the 7 day experimental period, at the end of which the medium was aspirated and cells were scraped with $2 \mathrm{ml}$ of methanol. Lipids were extracted with $4 \mathrm{ml}$ of chloroform at room temperature for $15 \mathrm{~min}$ after which phase separation was accomplished by addition of $1.2 \mathrm{ml}$ of $1.0 \mathrm{~N} \mathrm{HCl}$ followed by vortexing and centrifugation for $10 \mathrm{~min}$ at $1000 \times \mathrm{g}$. The lower phase was washed three times with $2.6 \mathrm{ml}$ of chloroformmethanol- $0.1 \mathrm{~N} \mathrm{HCl}(3: 48: 47)$, evaporated under nitrogen and reconstituted into $0.5 \mathrm{ml}$ of chloroform. The extracts from eight incubations were pooled, applied to the silicic acid column and fractionated as above. The samples and a "standard" consisting of the presumed transphosphatidylation product of sorbitol and phosphatidylcholine as described above were applied to pre-oxalated $20 \mathrm{~cm} \times 20 \mathrm{~cm}, 250 \mu \mathrm{m}$, silica gel $\mathrm{H}$ plates and developed twice in a solvent system containing chloroform-methanol-28\% $\mathrm{NH}_{3}(65: 25: 5)$. The silica gel bands corresponding to the "standard" were scraped along with bands corresponding to phosphatidylcholine, phosphatidic acid and an area devoid of bands and lipids were re-extracted and hydrolysed as described above. The liberated water-soluble compounds were analysed by gas-liquid chromatography. In another experiment, RPE 91 cells were exposed to $300 \mathrm{mmol} / 1$ glucose for 1 week and treated as above for the detection of sorbitol-containing phospholipids. 


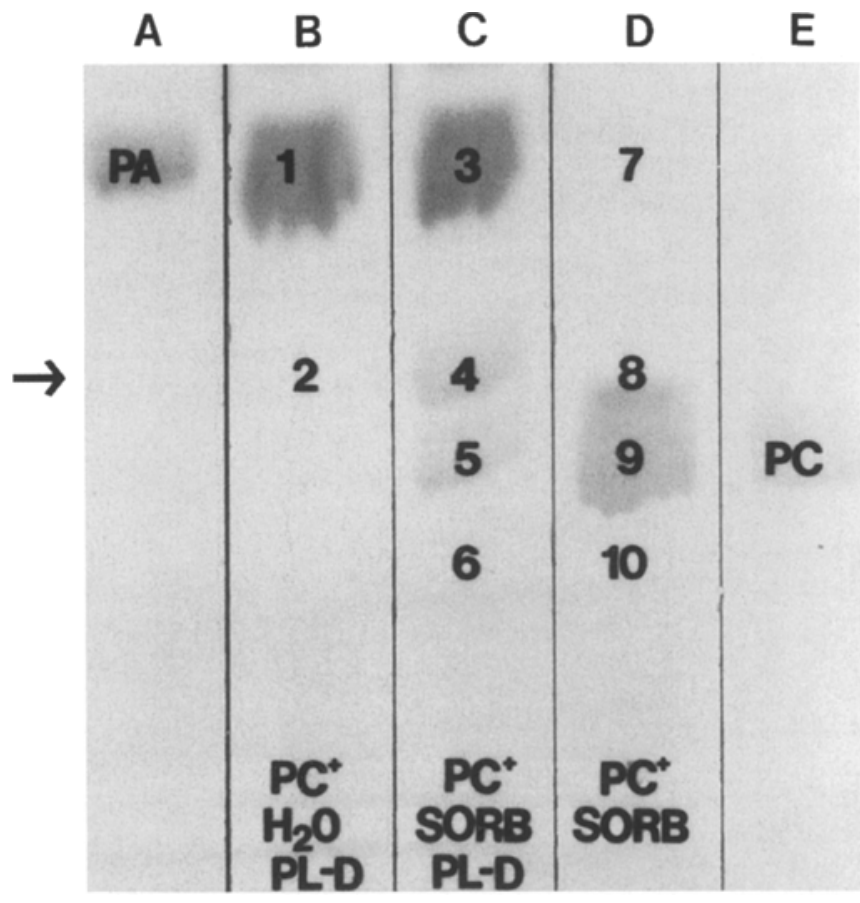

Fig. 1. Thin layer chromatographic separation of in vitro incorporation of sorbitol into phosphatidylcholine by peanut phospholipase D (PL-D). Phosphatidylcholine (PC) was incubated for $4 \mathrm{~h}$ with $3.0 \mathrm{~mol} / \mathrm{l}$ sorbitol (SORB) (lane D), PL-D (lane B), or both (lane C), and the products separated by thin layer chromatography. Reference lipids were phosphatidic acid (PA) (lane A) and PC (lane E). Arrow indicates reaction product presumed to be phosphatidylsorbitol, seen in lane C. No phosphatidylsorbitol-like product was evident in any regions of the thin layer chromatography plate except that which corresponded to the $\mathrm{Rf}$ of phosphatidylsorbitol including the area devoid of visible bands

\section{Results}

Transphosphatidylation of sorbitol and phosphatidylcholine. Incubation of phosphatidylcholine with peanut PL-D, $3.0 \mathrm{~mol} / 1$ sorbitol, or both, yiclded the lipid fractions illustrated in Figure 1. In the absence of sorbitol, peanut PL-D hydrolysed phosphatidylcholine completely and yielded phosphatidic acid $(\mathrm{Rf}=0.88)$ (band 1 in lane $\mathrm{B})$. Incubation of phosphatidylcholine and $3.0 \mathrm{~mol} / \mathrm{l}$ sorbitol without peanut PL-D left the phosphatidylcholine band $(\mathrm{Rf}=0.53)$ (band 9 in lane $\mathrm{D})$ intact. Incubation of phosphatidylcholine with both $3.0 \mathrm{~mol} / 1$ sorbitol and peanut PL-D produced a new lipid $(\mathrm{Rf}=0.62)$ distinct from phosphatidylcholine and phosphatidic acid (band 4 in lane $\mathrm{C}$ ). Note that the presence of sorbitol preserved some phosphatidylcholine despite the presence of PL-D, reflecting either inhibition of phosphatidylcholine hydrolysis by sorbitol, or resynthesis of phosphatidylcholine from the novel product.

Lipids contained in silica gel bands 1-10 were reextracted, hydrolysed and analysed by trimethylsilyl or aldonitrile-acetate gas-liquid chromatography as described in in the Materials and methods section.
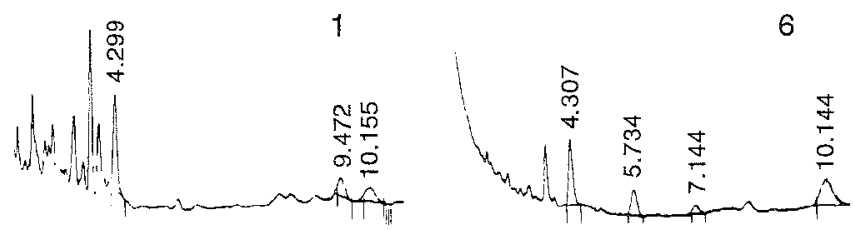

2

7
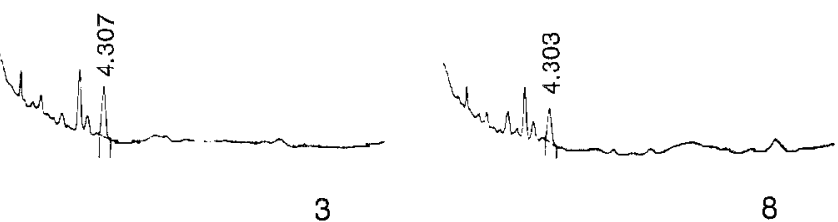

8

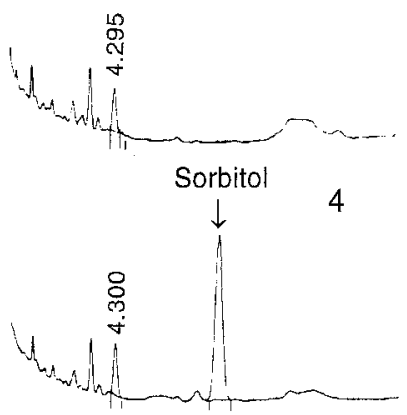

5
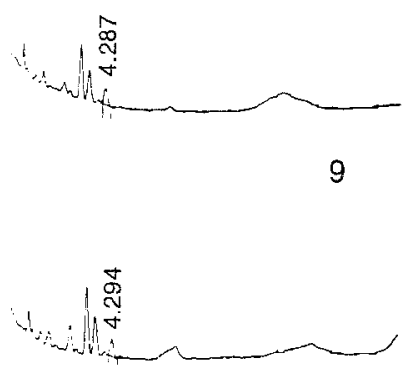

10
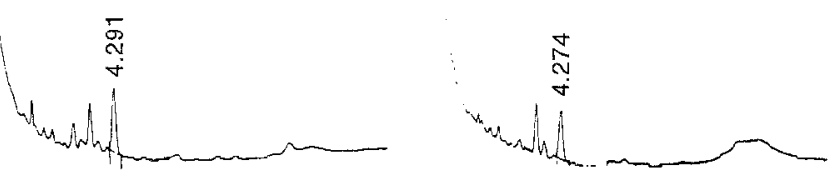

Fig. 2. Gas-liquid chromatograms of the trimethylsilylated hydrolysate products of the different bands identified in Figure 1. Numbers above each chromatogram correspond to the the numbers on Figure 1. Sorbitol (arrow) was identified only in the hydrolysate of band 4 of lane $C$ in Figure 1, presumed to be phosphatidylsorbitol

Examples of the trimethylsilyl gas-chromatograms are shown in Figure 2. The numbers of the chromatograms correspond to those of the parent silica-gel phospholipid bands identified in Figure 1. A water soluble compound that co-eluted with sorbitol was identified only in the sample from band 4 . These two experiments demonstrate that a novel phospholipid formed from phosphatidylcholine, sorbitol and peanut PL-D in vitro liberates a water-soluble compound cochromatographing with sorbitol upon re-exposure to peanut PL-D; thus the behaviour of this novel compound, phosphatidylsorbitol, is consistent with a transphosphatidylation product of phosphatidylcholine and sorbitol, with one of the six hydroxy groups of sorbitol in presumed phosphodiesteric linkage with the diglyceride moicty. Figures 3 and 4 indicate that this putative transphosphatidylation occurs in a time- and concentration-dependent fashion. Figure 3 illustrates the time-dependent accumulation over $4 \mathrm{~h}$ of the thin layer chromatography resolved reaction product in crude ("- column") and columnfractionated ("+ column") extracts. In Figure 4, ex- 


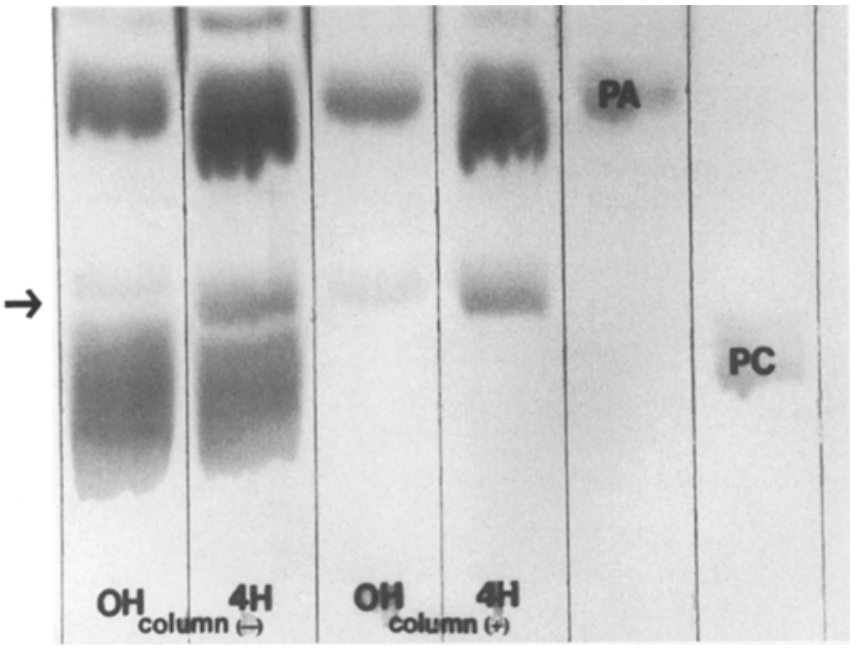

Fig. 3. Time-dependent formation of phosphatidylsorbitol. PC, PL-D and $3.0 \mathrm{~mol} / \mathrm{l}$ sorbitol were incubated for $0 \mathrm{~h}(0 \mathrm{H})$ or $4 \mathrm{~h}$ $(4 \mathrm{H})$. Reference lipids were PA and PC. Thin layer chromatograms of samples before ("column (-)") and after ("column $(+)$ ") column chromatographic pre-purification. Arrow indicates reaction product presumed to be phosphatidylsorbitol

tracts from $10 \mathrm{ml}, 5 \mathrm{ml}$ and $0.5 \mathrm{ml}$ aliquots of incubations with $0.03,0.3$ and $3.0 \mathrm{~mol} / 1$ sorbitol respectively were subjected to silica gel thin layer chromatography. The product from incubations with 0.3 and $3.0 \mathrm{~mol} / \mathrm{l}$ sorbitol were clearly visualized by iodine vapour. The product in the $10-\mathrm{ml}$ aliquot of the incubation with $0.03 \mathrm{~mol} / \mathrm{l}$ sorbitol was below the level of detection by iodine vapour, but phospholipid with the expected Rf was detected by molybdate phosphorus assay [26] (data not shown).

Transphosphatidylation of other polyols and glucose. The incubation of saturated aqueous solutions (at room temperature) of galactitol, mannitol and glucose with phosphatidylcholine and peanut PL-D under the conditions described above yielded phospholipids with chromatographic characteristics similar to that of phosphatidylsorbitol (Fig.5). The products of a 10 -ml aliquot of incubations with $0.15 \mathrm{~mol} / 1$ galactitol, $0.5 \mathrm{~mol} / 1 \mathrm{mannitol}$ and $1.5 \mathrm{~mol} / \mathrm{l}$ glucose were fractionated by silicic acid column chromatography and applied to silica gel thin layer chromatographic plates along with a $0.5 \mathrm{ml}$ aliquot from an incubation with $3.0 \mathrm{~mol} / 1 \mathrm{sorbitol}$. Although an accurate quantitative assay was not performed, glucose consistently formed less presumed transphosphatidylation product than galactitol, mannitol or sorbitol despite higher substrate concentration and size of sample, suggesting that sugar alcohols have higher activity for transphosphatidylation by peanut PL-D than glucose.

Transphosphatidylation of sorbitol by rat brain synaptosomes. To determine whether mammalian PL-D could transphosphatidylate sorbitol and phosphatidylcholine, a rat brain synaptosomal fraction with high PL-D activity [27] was incubated with $3.0 \mathrm{~mol} / \mathrm{l}$

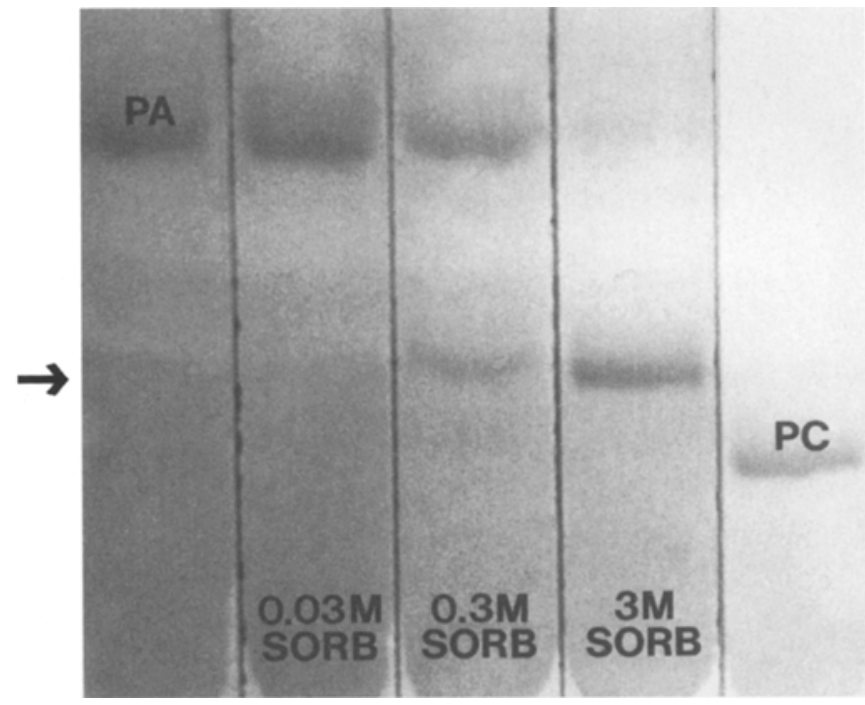

Fig.4. Concentration-dependent formation of phosphatidylsorbitol. PC, PL-D, and 0.03, 0.3 or $3.0 \mathrm{~mol} / \mathrm{l} \mathrm{SORB}$ were incubated for 4 h. Reference lipids were PA and PC. Arrow indicates reaction product presumed to be phosphatidylsorbitol

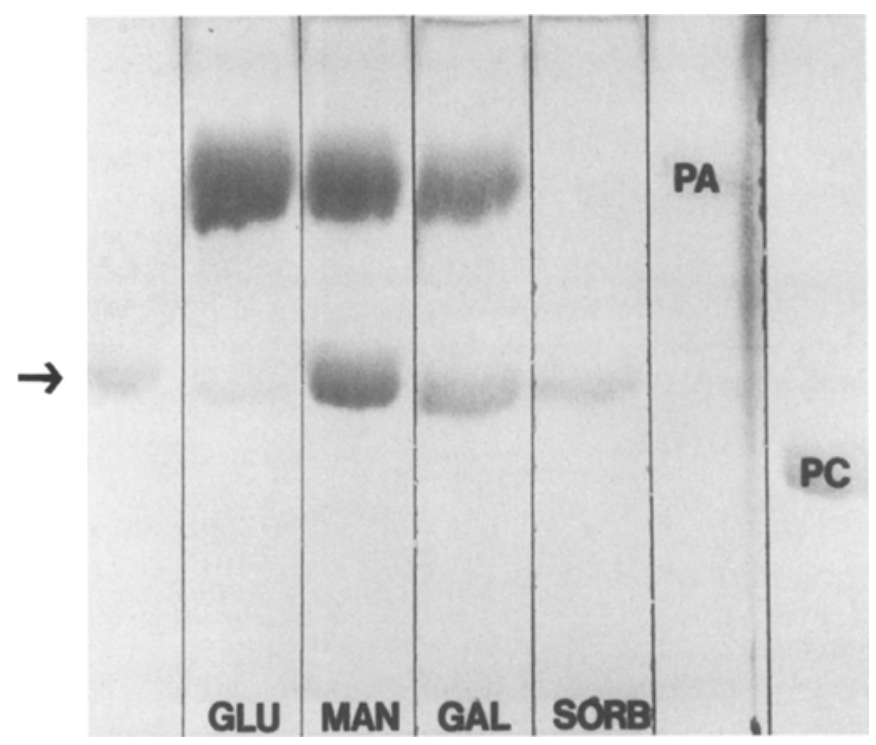

Fig. 5. Phosphatidylpolyol formation from glucose, mannitol, galactitol and sorbitol. PC and PL-D were incubated with $1.5 \mathrm{~mol} / 1$ glucose (GLU), $0.5 \mathrm{~mol} / 1$ mannitol (MAN), $0.15 \mathrm{~mol} / 1$ galactitol (GAL), or $3.0 \mathrm{~mol} / \mathrm{l}$ sorbitol (SORB) for $4 \mathrm{~h}$. Reference lipids were phosphatidylsorbitol (PSorb prepared as illustrated in Fig. 1), PA and PC. The amount of sample applied at the origin varied. Arrow indicates reaction product presumed to be phosphatidylsorbitol

sorbitol and $\left[{ }^{14} \mathrm{C}\right]$-phosphatidylcholine. Lipids were extracted and separated by silica-gel thin layer chromatography as described in the Materials and methods section. The autoradiogram of the silica gel plate in Figure 6 revealed a major radioactive band corresponding to unchanged $\left[{ }^{14} \mathrm{C}\right]$-phosphatidylcholine and a second radioactive band with a $\mathrm{Rf}$ value identical to that of phosphatidylsorbitol standard (arrow). A very weak radioactive band corresponding to phos- 


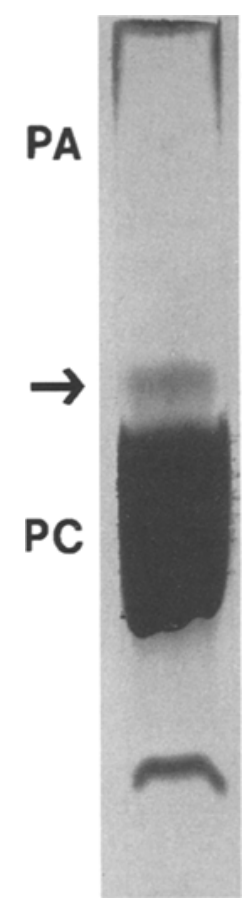

Fig. 6. Transphosphatidylation of sorbitol by rat brain synaptosomes. Autoradiogram of a thin layer chromatographic separation of lipids extracted from a rat brain synaptosomal fraction having high PL-D activity after incubation with $3.0 \mathrm{~mol} / \mathrm{l}$ sorbitol and $\left[{ }^{14} \mathrm{C}\right]$-phosphatidylcholine. Radioactivity was most intense in a band migrating identically to phosphatidylcholine (PC) and faint radioactivity was seen in a band migrating identically to phosphatidic acid (PA). A radioactive band with characteristics of phosphatidylsorbitol (arrow) is visible just above the intense PC band. An unknown product is present below the PC band

phatidic acid was also obtained, as well as an additional radioactive band below phosphatidylcholine that could represent an additional unknown phospholipid produced by base-exchange. This observation suggests that mammalian PL-D can catalyse the transphosphatidylation of sorbitol and phosphatidylcholine.

Phosphatidylsorbitol in RPE. Lipids extracted from RPE 91 cells exposed to 5 or $20 \mathrm{mmol} / 1$ glucose, or $20 \mathrm{mmol} / \mathrm{l}$ glucose plus the aldose reductase inhibitor sorbinil were purified by column chromatography and separated by silica gel thin layer chromatography using chloroform-methanol- $\mathrm{NH}_{3}$ which separates phosphatidylsorbitol, phosphatidylserine and phosphatidylinositol. Silica gel regions corresponding to phosphatidylsorbitol standard, phosphatidylcholine, phosphatidic acid and an area containing no detectable bands on thin layer chromatography were scraped, re-extracted, hydrolysed, trimethylsilated and analysed by gas-liquid chromatography. Although lipid-bound sorbitol was not detected in $5 \mathrm{mmol} / \mathrm{l}$ glucose, a small but clear sorbitol peak was detected in the $20 \mathrm{mmol} / \mathrm{l}$ glucose condition and incubation with an aldose reductase inhibitor lowered this peak, as illustrated in Figure 7. No sorbitol was detected in any of the other areas tested. The recovery rate of $\alpha$-methylmannopyranoside as an internal standard was similar in these conditions. In RPE 91 cells exposed to $300 \mathrm{mmol} / \mathrm{l}$ glucose for 1 week and extracted by the same method, gas-liquid chromatography of aldonitrile acetate derivatives yielded a peak in the area of sorbitol, confirming the presence of sorbitol in the phospholipid hydrolysate extracted from glucose-exposed RPE cells using two different gas-
A $5 \mathrm{mmol} / \mathrm{l}$ Glucose

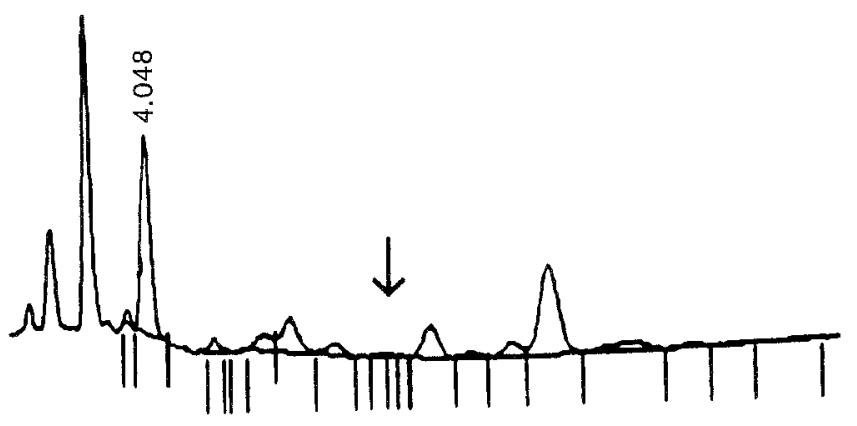

B $20 \mathrm{mmol} / \mathrm{l}$ Glucose

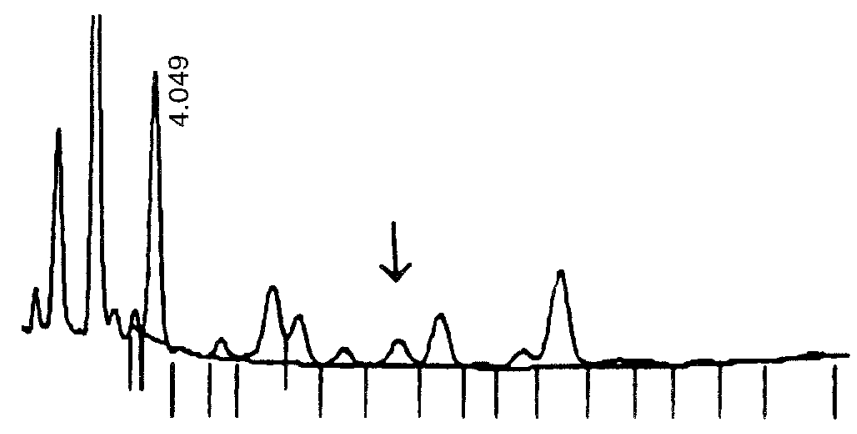

C $20 \mathrm{mmol} / \mathrm{l}$ Glucose + ARI

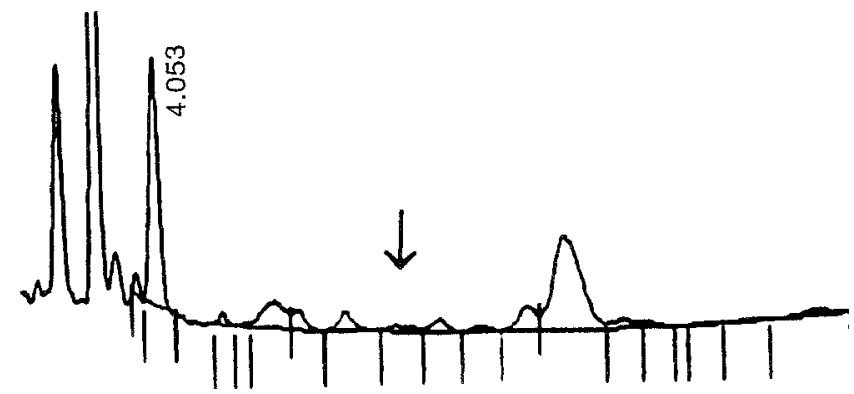

Fig. 7. Formation of phosphatidylsorbitol by glucose-exposed human retinal pigment epithelial cells and its inhibition by the aldose reductase inhibitor sorbinil. Cells were incubated with $5 \mathrm{mmol} / 1(A)$ or $20 \mathrm{mmol} / \mathrm{l}$ glucose without $(B)$ or with $(C)$ the aldose reductase inhibitor (ARI) (sorbinil $10 \mu \mathrm{mol} / 1$ ) for 7 days. Phospholipids were extracted and purified as described in Materials and methods and previous Figures. The bands corresponding to Psorb were hydrolysed and trimethylsilated. These were separated and analysed by gas-liquid chromatography as described in Materials and methods. Arrow indicates the retention time of the sorbitol standard

liquid chromatography methods. These observations suggest that a phosphatidylsorbitol-like compound is accumulated in RPE cells exposed to $20 \mathrm{mmol} / \mathrm{l} \mathrm{glu}$ cose or $300 \mathrm{mmol} / \mathrm{l}$ glucose by an aldose reductasesensitive pathway.

\section{Discussion}

PL-D activity catalyses the general reaction:

phosphatidyl-R + R' - OH $\leftarrow \rightarrow$ phosphatidyl-R' $+\mathrm{R}-\mathrm{OH}$ 
When R' = H, PL-D hydrolyses phospholipids, yielding phosphatidic acid and a free polar headgroup (e.g. choline or ethanolamine). In the presence of a primary alcohol, the preferred reaction is transphosphatidylation i.e. displacement of the primary polar headgroup by the primary alcohol [28]. Previous studies have demonstrated that PL-D catalyses the formation of phosphatidylethanol in ethanol-exposed mammalian tissues [13-15] and it has been speculated that this abnormal phospholipid could alter membrane phospholipid composition and function in ethanol intoxication. Sorbitol, a polyol rather than a primary alcohol, nevertheless could function as a substrate for transphosphatidylation by virtue of its two primary (and possibly its four secondary) hydroxy moieties. The present study demonstrates that sorbitol and phosphatidylcholine in the presence of peanut PL-D yield a novel sorbitol-containing phospholipid by presumed transphosphatidylation similar to that described in the PL-D-catalysed formation of phosphatidylethanol from ethanol and phosphatidylcholine [13-15]. Although it has been tentatively labelled phosphatidylsorbitol, the chemical structure of this presumed transphosphatidylation product of sorbitol and phosphatidylcholine has yet to be fully characterized. The capacity to undergo transphosphatidylation is not uniquely confined to sorbitol but rather is shared with other polyols of similar molecular weight such as mannitol and galactitol, and perhaps glucose as well. Transphosphatidylation of polyols is not limited to plant PL-D, but rather is shared by mammalian PL-D activity, and would appear to occur in human cells that accumulate sorbitol when exposed to high concentrations of glucose. Incubation of phosphatidylcholine with $3.0 \mathrm{~mol} / \mathrm{l}$ sorbitol and peanut PL-D produced a novel sorbitol-containing phospholipid with an Rf value intermediate between that of phosphatidylcholine and phosphatidic acid, thought to be phosphatidylsorbitol.

The minimal concentration of sorbitol in the studies with peanut PL-D was $0.03 \mathrm{~mol} / \mathrm{l}$, or about 30 fold higher than the tissue or cellular sorbitol content after exposure to hyperglycaemic concentrations of glucose [4]. Although phosphatidylsorbitol product could not be visualized in thin layer chromatograms from $0.03 \mathrm{~mol} / 1$ sorbitol, nanomolar levels of a phospholipid with an $\mathrm{Rf}$ identical to phosphatidylsorbitol were detected by the colorimetric phosphorous assay with molybdate, which also indicated that phosphatidylsorbitol formation followed a nearly linear increase with sorbitol concentration over the range $0.03-3.0 \mathrm{~mol} / \mathrm{l}$ sorbitol (data not shown). This observation suggests that phosphatidylsorbitol could be increased over the range of sorbitol concentration associated with physiological hyperglycaemic. Moreover, the demonstration that mammalian as well as plant PL-D catalyses transphosphatidylation of sorbitol, and that a phosphatidyl- sorbitol-like compound accumulates in RPE 91 cells exposed to $20 \mathrm{mmol} / \mathrm{l}$ glucose by an aldose reductase inhibitor-sensitive mechanism supports the potential pathophysiological relevance of phosphatidylsorbitol to diabetic complications.

Glucose-induced sorbitol accumulation has been implicated in the pathogenesis of various chronic complications of diabetes including neuropathy, retinopathy, nephropathy, cataract formation, and micro- and macrovasculopathy [29]. Despite the more than three decades that have elapsed since sorbitol accumulation was first described in the cataractous lenses of diabetic rats $[30,31]$, the overall importance and the details of the biochemical link between sorbitol pathway activity and diabetic complications remain clouded, although aldose reductase inhibitors are now utilized for the treatment of diabetic complications in many countries. Increased metabolism of glucose to sorbitol by aldose reductase is implicated in selective depletion of intracellular myo-inositol pools, which in turn appears to limit the synthesis of phosphoinositides involved with membrane function including $\mathrm{Na} / \mathrm{K}$-ATPase regulation, and signal transduction $[2-4,6,7,32,33]$. The nature of the relationship between sorbitol accumulation and myo-inositol depletion is complex and controversial, but perhaps most easily placed into perspective by the currently emerging view that these two compounds function as alternative intracellular osmolytes, such that elevation of one produces depletion of the other [1]. Similarly complex and controversial is the role of intracellular myo-inositol depletion in the modulation of phosphatidylinositol synthesis. Recent studies in RPE 91 cells suggested the presence of multiple intracellular metabolic pools of myo-inositol, depletion of which had varying effects on the rate of phosphatidylinositol synthesis [4]. However, sorbitol, added to the incubation medium at a concentration of $10 \mathrm{mmol} / \mathrm{l}$, appeared to independently inhibit the phosphatidylinositol synthase reaction in myo-inositol depleted cells [4] by an unknown mechanism. Although effects linked to the subsequent oxidation of the added sorbitol to fructose by sorbitol dehydrogenase provide a possible explanation [9] the speculation that transphosphatidylation of sorbitol might also contribute cannot be excluded, although lipid-bound sorbitol could not be detected under these circumstances by gas-liquid chromatography (Nakamura J, Greene DA, unpublished observations). Whether incorporation of sorbitol-derived phospholipids into membrane structures could have effects on other membrane-associated enzymes or functions remains to be determined.

In summary, PL-D from plant and mammalian sources appears to possess the ability to incorporate sugar alcohols, and to some extent, sugars themselves, into membrane phospholipids by a presumed transphosphatidylation reaction. This reaction may 
provide a novel link between disorders of carbohydrate and sugar alcohol metabolism such as diabetes and alterations in membrane composition or function or both.

Acknowledgements. This research was supported by USPHS RO1-DK38304 (DAG) and the Michigan Diabetes Research and Training Center (P60-DK20572) (DAG). The authors would like to acknowledge the expert consultation and scientific guidance of Dr. A. K. Hajra in the Department of Pharmacology, the expert technical assistance of Ms. L. Beyer, and consultation provided by Dr.D. Martin of the Michigan Diabetes Research and Training Center Biochemistry Core Laboratory.

\section{References}

1. Burg MB, Kador PF (1988) Sorbitol, osmoregulation, and the complications of diabetes. J Clin Invest 81: 635-640

2. Winegrad AI (1987) Banting lecture 1986. Does a common mechanism induce the diverse complications of diabetes? Diabetes 36: 396-406

3. Greene DA, Lattimer SA, Sima AAF (1988) Perspectives in diabetes: are disturbances of sorbitol, phosphoinositide, and $\mathrm{Na}^{+}-\mathrm{K}^{+}$-ATPase regulation involved in the pathogenesis of diabetic neuropathy? Diabetes 37: 688-693

4. Nakamura J, Del Monte MA, Shewach D, Lattimer SA, Greene DA (1992) Inhibition of phosphatidylinositol synthase by glucose in human retinal pigment epithelial cells. Am J Physiol 262: E417-E426

5. Loy A, Lurie KG, Ghosh A, Wilson JM, MacGregor LC, Matschinsky FM (1990) Diabetes and the myo-inositol paradox. Diabetes 39: 1305-1312

6. Eichberg J, Zhu X (1992) Diacylglycerol composition and metabolism in peripheral nerve. Adv Exp Med Biol 318: $413-425$

7. Zhu X, Eichberg J (1990) 1,2-Diacylglycerol content and its arachidonyl-containing molecular species are reduced in sciatic nerve from streptozotocin-induceddiabetic rats. J Neurochem 55: 1087-1090

8. Thomas TP, Feldman EL, Nakamura J et al. (1993) Ambient glucose and aldose reductase-induced myo-inositol depletion modulate basal and carbachol-stimulated inositol phospholipid metabolism and diacylglycerol accumulation in human retinal pigment epithelial cells in culture. Proc Natl Acad Sci USA 90: 9712-9716

9. Williamons JR, Chang K, Frangos M et al. (1993) Hyperglycemic "pseudohypoxia" and diabetic complications. Diabetes 42: 801-813

10. Stevens MJ, Feldman EL, Dananberg J et al. (1993) Nitric oxide deficiency mediates nerve conduction slowing in experimental diabetic neuropathy. Diabetologia 36: A51 (Abstract)

11. Greenberg L, Urbanes AQ, Shayman JR (1992) Unimpaired formation of hormone-stimulated inositol trisphosphate in human mesangial cells under hyperglycemic conditions. Biochim Biophys Acta 1138: 229-235

12. Heller D (1978) Phospholipase D. In: Paoletti R, Kritchevsky D (eds) Advances in lipid research, Vol.16. Academic Press, New York 267-326

13. Alling C, Gustavsson L, Anggard E (1983) An abnormal phospholipid in rat organs after ethanol treatment. FEBS Lett 152: 24-28

14. Alling C, Gustavsson L, Mansson JE, Benthin G, Anggard E (1984) Phosphatidylethanol formation in rat organs after ethanol treatment. Biochim Biophys Acta 793: 119 122

15. Kobayashi M, Kanfer JN (1987) Phosphatidylethanol formation via transphosphatidylation by rat brain synaptosomal phospholipase D. J Neurochem 48: 1597-1603

16. Bondeson J, Sundler R (1987) Phosphatidylethanol counteracts calcium-induced membrane fusion but promotes proton-induced fusion. Biochim Biophys Acta 899: 258264

17. Del Monte MA, Rabbani R, Diaz TC et al. (1991) Sorbitol, myo-inositol, and rod outer segment phagocytosis in cultured hRPE cells exposed to glucose. In vitro model of myoinositol depletion hypothesis of diabetic complications. Diabetes 40: 1335-1345

18. MacGregor LC, Rosecan LR, Laties AM, Matschinsky FM (1986) Altered retinal metabolism in diabetes. I. Microanalysis of lipid, glucose, sorbitol, and myo-inositol in the choroid and in the individual layers of the rabbit retina. $J$ Biol Chem 261: 4046-4051

19. MacGregor LC, Matschinsky FM (1986) Altered retinal metabolism in diabetes. II. Measurement of sodium-potassium ATPase and total sodium and potassium in individual retinal layers. J Biol Chem 261: 4052-4058

20. MacGregor LC, Matschinsky FM (1985) Treatment with aldose reductase inhibitor or with myo-inositol arrests deterioration of the electroretinogram of diabetic rats. J Clin Invest 76: $887-889$

21. Guerrant GO, Moss CW (1984) Determination of monosaccharides as aldonitrile, o-methyloxime, alditol, and cyclitol derivatives by gas chromatography. Anal Chem 56: 633-638

22. Stevens MJ, Henry DN, Thomas TP, Killen PD, Greene DA (1993) Aldose reductase gene expression and osmotic dysregulation in cultured human retinal pigment epithelial cells. Am J Physiol 265: E428-E438

23. Cotman CW, Matthews DA (1971) Synaptic plasma membranes from rat brain synaptosomes: isolation and partial characterization. Biochem Biophys Acta 249: 380-394

24. Del Monte MA, Maumenee IH (1980) New techniques for in vitro culture of human retinal pigment epithelium. Birth Defects: Orig Artic Ser 16: 327-338

25. Henry DN, Del Monte M, Greene DA, Killen PD (1993) Altered aldose reductase gene regulation in cultured human retinal pigment epithelial cells. J Clin Invest 92: 617623

26. Duck-Chong CG (1979) A rapid sensitive method for determining phospholipid phosphorus involving digestion with magnesium nitrate. Lipids 14: 492-497

27. Hattori H, Kanfer JN (1985) Synaptosomal phospholipase $D$ potential role in providing choline for acetylcholine synthesis. J Neurochem 45: 1578-1584

28. Dawson RM (1967) The formation of phosphatidylglycerol and other phospholipids by the transferase activity of phospholipase D. Biochem J 102: 205-210

29. Dvornik D (1987) Aldose reductase inhibition - an approach to the prevention of diabetic complications. Mac Graw-Hill, New York

30. Van Heyningen R (1959) Formation of polyols by the lens of the rat with 'sugar' cataract. Nature 184: 194-195

31. Van Heyningen R (1959) Metabolism of xylose by the lens. 2. Rat lens in vivo and in vitro. Biochem J 73: 197-207

32. Yorek MA, Dunlap JA, Ginsberg BH (1988) Effect of increased glucose levels on $\mathrm{Na}^{+} / \mathrm{K}^{+}$-pump activity in cultured neuroblastoma cells. J Neurochem 51: 605-610

33. Lattimer SA, Sima AAF, Greene DA (1989) In vitro correction of impaired $\mathrm{Na}^{+}-\mathrm{K}^{+}$-ATPase in diabetic nerve by protein kinase C agonists. Am J Physiol 256: E264 E269 